\title{
Towards a Knowledge-Based Fixture Designers' Assistant
}

\author{
E. Caillaud* and D. Noyes \\ ENIT, avenue d'Azereix, 65016 Tarbes, FRANCE, \\ phone: (33)62.44.27.16,e-mail: noyes@enit.fr \\ *Now at École des Mines d'Albi, route de Teillet, 81013 Albi, FRANCE, \\ phone: (33) 63.49.30.92, e-mail: caillaud@enstimac.fr
}

\begin{abstract}
As the fixture design is a key step in planning process, the aim of our research is to develop a fixture designers' assistant integrated in the life cycle of the part. In order to develop a knowledge-based system for fixture design, we have structured the fixture designers' knowhow and we have implemented it in an expert system.

This paper focuses on the knowledge capitalisation process and the necessity of the knowledge formalisation.

The following points are thrown into relief in this paper:

- the methodology used to model the fixture designers' knowledge,

- the results of this modelisation: a structuration of the fixture design process,

- an implementation of the procedure by means of an expert system.
\end{abstract}

\section{Keywords}

Computer-Aided Engineering, Applications of Expert Systems, Knowledge Based Systems, Flexible Production Systems, Methods Department, Fixture.

\section{INTRODUCTION}

Fixture design is a significant step in the product life cycle. The final quality of the machining of the part and the possibility to use the optimal cutting conditions depend strongly on the fixture quality. The amount of papers about fixture design automation shows how substantial fixture design is (see the literature survey in [Hargrove and Kusiak 94]), however these works do not consider the fixture design in the life cycle of the whole product and do not insist on the fixture designers' know-how.

The aim of our research is to develop a fixture designers' assistant. This tool will allow to decrease the design time and to structure the necessary knowledge for fixture design. The 
basis for the simultaneous design of the fixture and the part is the structuration of the knowhow.

The objective of this paper is to present the adequate approach to model the fixture design process. The paper is divided into three sections. The first section explains the methodology used to model the fixture designers' knowledge. An expression of the procedure for fixture design based on fixture designers' rules is developed in the second section. Its implementation by means of an expert system is presented in the third section.

\section{METHODOLOGY TO MODEL THE FIXTURE DESIGNERS' KNOW-HOW}

In order to model a common knowledge on fixture design, we studied the fixture design process in several firms.

A fundamental prerequisite is to locate precisely the different steps of the fixture life cycle in the various departments of the firm: design department/ method department/ workshop.

First, we defined a generic functional model according to the SADT ${ }^{\mathrm{TM}}$ formalism [Softech 76] presented in [Caillaud et al. 93]. This model is the framework of the knowledge domain.

Once the persons having the knowledge about fixture have been identified, an extraction of the know-how has been led. On the basis of different knowledge extraction approaches (such as MACAO [Aussenac 89]), we defined the following methodology:

1. Analysis of the way of working of fixture designers on real examples,

2. Formalisation of the way of designing fixtures on a procedure,

3. Validation of the procedure with the designers,

4. Completion of the knowledge with "basic examples",

5. Expression of the rules with the experts,

6. Formalisation of the rules and data,

7. Completion and validation of the rules

8. Implementation of the rules in an expert system shell,

9. Validation of the expert system with the fixture designers.

The results of this methodology are presented in the schema of figure 1. 


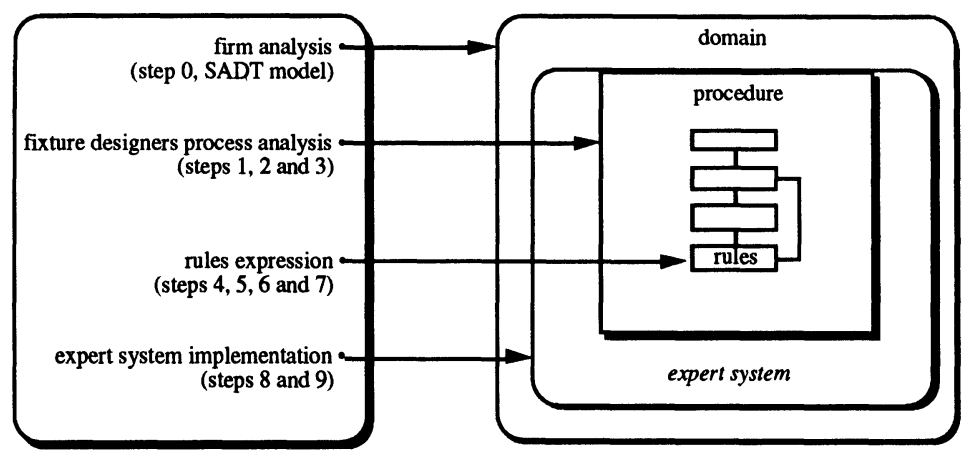

Figure 1 Methodology for knowledge extraction.

The main results of this methodology are given in the next sections.

\section{FIXTURE DESIGN PROCESS}

We propose a procedure for fixture design based on an analysis of the fixture design process.

The fixture design rules extracted from the firms' experience are not formalised and are sometimes contradictory. Moreover, their use is empiric. The proposed procedure is based on the expert rules we have formalised. This procedure is original because neither schoolbooks nor scientific papers propose a complete procedure for fixture design. This procedure results from a synthesis of studies made in different firms chosen since they are representative in small batch manufacturing. It deals with prismatic parts.

The knowledge of fixture design is formalised in steps based on the fixture designers' knowledge.

Design brings another dimension to knowledge: the functions of the fixture to be designed are progressively defined. We express this progressive definition by various abstraction levels for each function of the fixture. The procedure for fixture design defines progressively each function in a precise order.

Let us remind that the basic fixturing functions for the part machining consist in positioning, clamping and supporting the part. Auxiliary functions consist in linking and tightening the contact elements with the machine-tool table. These different functions are linked and the achievement of a function influences the realisation of the next ones. Finally, the achievement of the whole functions must keep the tool paths free and allows a good lubrication and a correct chip evacuation (see [Boyes 89] for examples of fixtures).

The fixture design is based on the application of experts' rules. The activation of these rules induces three abstraction levels in the definition of the fixture: functional level, technological level, physical level. At a functional level, the surfaces of the part where the function must be applied are chosen. At the technological level, the technological solution is 
detailed: type, number and position of the contact elements. At the physical level, the real elements corresponding to the requirements are chosen and located.

We present in figure 2, the diagram of the fixture design procedure.

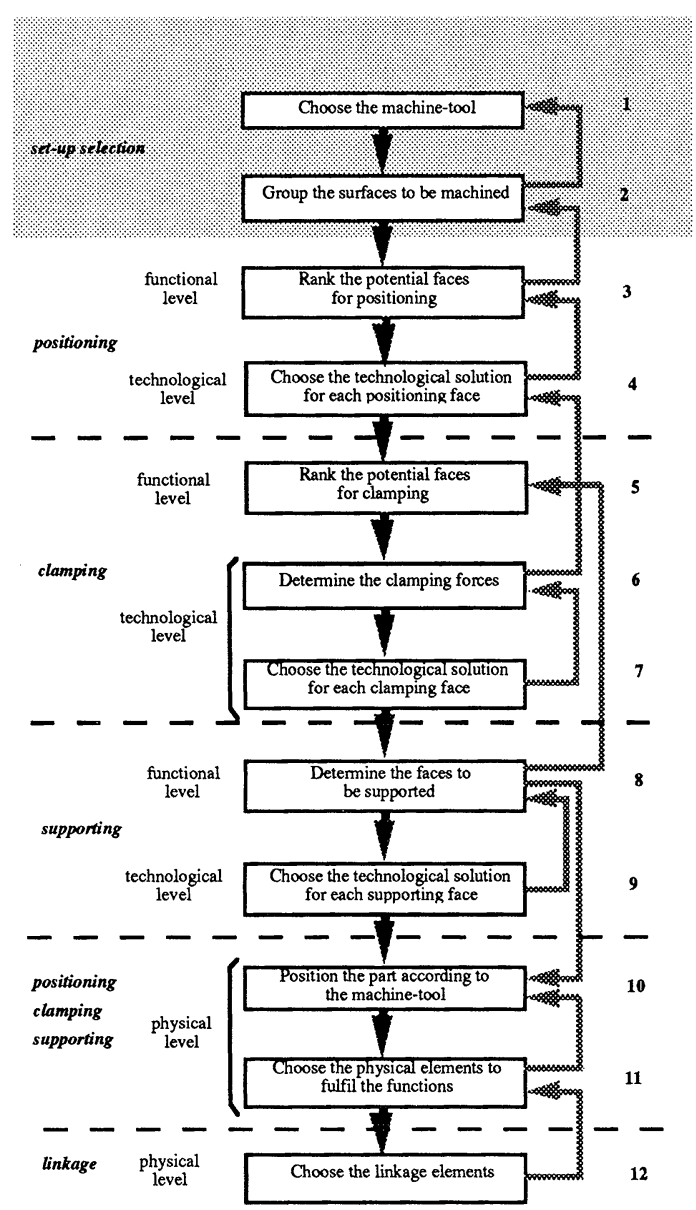

Figure 2 Procedure for fixture design.

An important feature of this diagram is the reactivity of design by its feed-backs. The fixture designer considers only the current step of design. If the designer encounter a difficulty, he goes back to the previous step: he does not reconsider the whole solution.

For each step, we present the objective, the necessary data, the output data. The rules are listed as production rules. 
In fact, the fixture designers do not express all the rules. They explain how to define one solution from data they have implicitly formatted.

In order to develop several solutions in parallel (as it is possible with an expert system), we have to define some different types of rules. We consulted the experts to define some evaluation rules to compare several solutions and some selection rules in order to develop the "best" ones.

Finally, we define on this basis four types of rule bases :

- rule bases to elaborate relevant data for fixture design from the part CAD/CAM (type RI),

- rule bases to define solutions from data (type RII),

- rule bases to evaluate partial or global solutions (type RIII),

- rule bases to select acceptable solutions (type RIV).

These different rules are presented in figure 3.

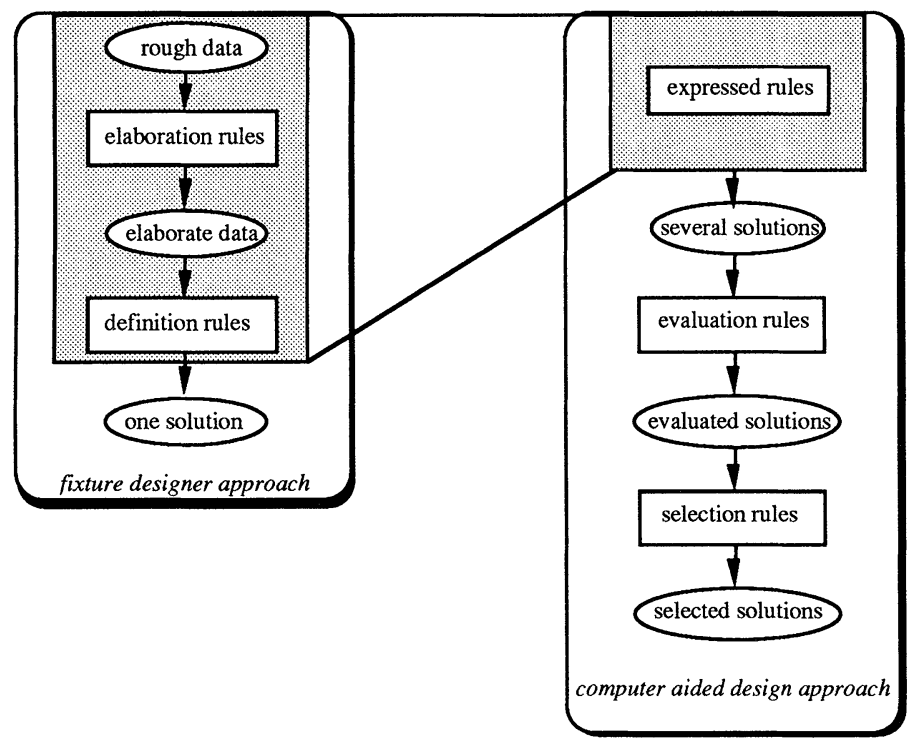

Figure 3 Different types of rules.

We present the following rules as examples of the different types.

Let us remind that experts generally mix the definition, the evaluation and the selection of the solution.

Considering the relevant data needed for fixture design, we have distinguished the "rough" data, directly extractable for the part CAD model from the "elaborate" data specially defined for fixture design. 
Data are the link between the part CAD/CAM system and the fixture design support system.

Table 1 Examples of the types of rules

\begin{tabular}{|l|l|}
\hline Type of rule & Example of rule \\
\hline RI & $\begin{array}{l}\text { If a surface is opposed to important cutting forces, } \\
\text { Then its opposition to cutting forces is considered as important. }\end{array}$ \\
\hline RII & $\begin{array}{l}\text { If a surface the main positioning surface, } \\
\text { it is plane, } \\
\text { it is regular, } \\
\text { it has been machined, } \\
\text { it is plane, } \\
\text { it is accessible, } \\
\text { Then the number of positioning contact is 1, } \\
\text { positioning contact type is plane. }\end{array}$ \\
\hline RIII & $\begin{array}{l}\text { If a possible maintaining surface is not opposed to a full volume, } \\
\text { Then its mark is decreased of 4 points. }\end{array}$ \\
\hline RIV & $\begin{array}{l}\text { If a possible main positioning surface rank is 1 } \\
\text { its size is important } \\
\text { Then it is the main position surface of solution 1. }\end{array}$ \\
\hline
\end{tabular}

Notice that the evaluation is made by the decrease of the marks of the faces with the rules RIII.

The validation of the knowledge acquired is made through its implementation in an expert system shell and is presented in section 4.

\section{A KNOWLEDGE BASED SYSTEM FOR FIXTURE DESIGN}

In order to validate the acquired knowledge, two different axis must be studied: the logical aspect (completeness and consistency of the rule bases) and the semantic aspect (quality of the reasoning and results). Our main interest is the confidence in the answers given by the expert system. As knowledge acquisition is a difficult topic in fixture design (non formalised rules, contradictory and often not even expressed rules), we wanted to validate it in order to modify and complete it. Expert systems offer these possibilities.

Different books ([Barr et Feigenbaum 81], [Farreny et Ghallab 87]) develop the principles and the features of expert systems.

We developed the expert system with NEXPERT OBJECT ${ }^{\mathrm{TM}}$ [Neuron Data 91] (see [Caillaud et al. 95]). Our choice has been guided by the features of this expert system shell: integration possibilities to $\mathrm{CAD} / \mathrm{CAM}$ systems, portability and diffusion in industry.

More than 200 rules are implanted. The knowledge structure implantation is made according to the typology previously presented; i.e. rules are structured in different rule bases according to the concerned step of the procedure and their type.

The rule bases activity is managed by a control rule base. We present in figure 1 the framework of the rule bases structure. 
The corresponding rules are: data definition in rule base 0.1 , functional positioning in rule base 3 , technological positioning in rule base 4 , functional clamping in rule base 5 , technological clamping in rule bases 6 and 7, functional supporting in rule base 8 , technological supporting in rule base 9 .

Notice that all the shared data depend on the control knowledge base.

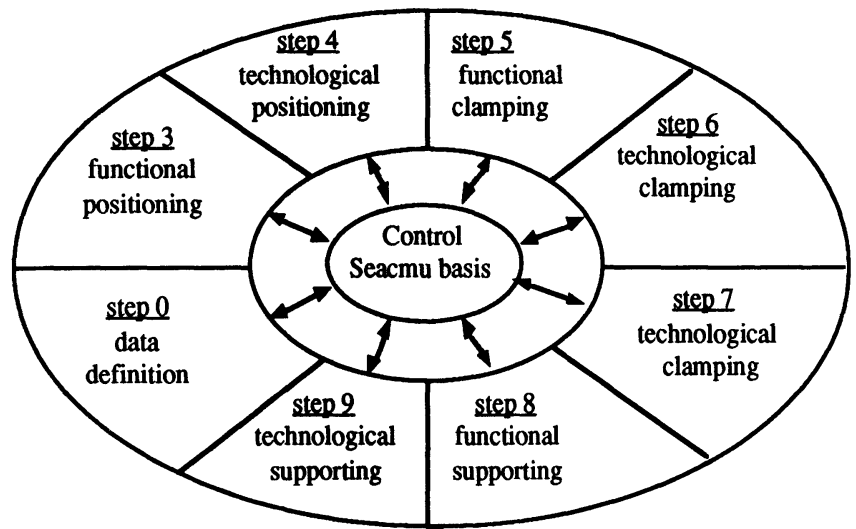

Figure 4 Knowledge bases organisation.

The use of this fixture designers' assistant provides an help for several aspects of the design:

- a procedural sequence of steps to study with the identification of the necessary data and the expected results,

- an evaluation procedure to estimate and compare different solutions with several criteria,

- a software which provides solutions for the main classical cases of fixture.

The expert system can not be considered as an automatic fixture designer but as a design support system. So, the designer can dedicate himself to the most difficult steps.

\section{CONCLUSIONS}

The aim of this study is to define a decision support system for fixture design integrated in the CAD/CAM life cycle of the part.

The results presented in this paper particularly concern the methodology used to model the fixture designers' knowledge and its main results. We modelled the necessary data of the part for fixture design in order to apply the experts' rules.

A version using NEXPERT ${ }^{\mathrm{TM}}$ as an expert system shell has been developed in order to exploit this knowledge structure. The expert system has been validated on relevant examples.

This knowledge structure allows the integration of the decision support system for fixture design to the CAD/CAM of the part. We actually work on the manipulation of data available (from CAD/CAM systems) in order to get efficiently the relevant data for fixture design. With this approach, we are going to the simultaneous design domain ([Kusiak and Wang 93] and [Sohlenius 92]). 


\section{ACKNOWLEDGEMENTS}

This paper presents parts of the results of a study supported by Association Nationale de la Recherche Technique, Ministère de la Recherche et de la Technologie through a contract CIFRE between Ecole Nationale d'Ingénieurs de Tarbes (ENIT) and CEntre Technique des Industries Mécaniques (CETIM). Contract $\mathrm{n}^{\circ}$ 183-90.

CETIM was involved in the BRITE-EURAM project IDEFIX $n^{\circ} 3480$ on modular fixtures design. The authors thank particularly MM. Anglerot and Padilla (CETIM) for their support to this project.

\section{REFERENCES}

Aussenac, N. (1989) Conception d'une méthodologie et d'un outil d'acquisition des connaissances expertes. Thèse de doctorat de 3ème cycle, Université Paul Sabatier, Toulouse.

Barr, A. and Feigenbaum, E.A. (1981) The handbook of artificial intelligence. William Kaufman Inc., New York.

Boyes, W.E. (1989) Handbook of jig and fixture design., SME, Dearborn (Michigan).

Caillaud, E., Noyes, D., Anglerot, G. and Padilla, P. (1993) Towards a simultaneous design of the part and the fixture, in APMS' 93 (ed. Elsevier), pp. 243-250, IFIP, Athens.

Caillaud, E., Noyes, D., Anglerot, G. and Padilla, P. (1995) Concurrent engineering: an expert system for fixture design, in ETFA' 95, (ed. IEEE), Vol. 1, pp. 137-144, INRIA, Paris.

Farreny, H. and Ghallab, M. (1987) Eléments d'intelligence artificielle . HERMES, Paris.

Hargrove, S.K. and Kusiak, A. (1994) Computer-aided fixture design: a review. International Journal of Production Research, Vol.32, n 4, pp. 733-753.

Kusiak, A. and Wang J. (1993) Efficient organizing of design activities. International Journal of Production Research, Vol. 31, $\mathrm{n}^{\circ} 4$, pp. 753-769.

Neuron Data (1991) NEXPERT User's Guide.

Softech Inc. (1976) SADT TM Author Guide.

Sohlenius, G. (1992) Concurrent engineering. Annals of the CIRP, Vol. 41, $\mathrm{n}^{\circ} 2$, pp. 645-655.

\section{BIOGRAPHY}

Emmanuel Caillaud received the Diploma in production engineering from the Ecole Nationale d'Ingenieurs de Tarbes, France, in 1990. He received his Ph.D. degree from the University of Bordeaux, France, in 1995. Since 1994, he has been an Assistant-Professor in the industrial engineering research centre of Ecole des Mines d'Albi, France. His research interests include know-how modelisation, simultaneous design and production management.

Daniel Noyes received his Ph.D. thesis from the Université Paul Sabatier de Toulouse, France, in 1975 then his "Docteur d'Etat" degree from the Institut National Polytechnique de Toulouse in 1987. Since 1977, he is Professor at the Ecole Nationale d'Ingénieurs de Tarbes, France. He is responsible of the "Production Automatisée" research team; his current research interests are in dependability evaluation and performance analysis of production systems. 